\title{
Entre o sagrado e o profano: identidades, paradoxos e ambivalências de prostitutas evangélicas do baixo meretrício de Belo Horizonte
}

\author{
JefFerson Rodrigues Pereira ${ }^{1}$ \\ José Vitor Palhares dos SANTOS ${ }^{1}$ \\ Alice GerLane CaRdoso da Silva ${ }^{1}$ \\ Kely CeSAR MARTINS de PaIVA ${ }^{1}$ \\ ALEXANDRE DE PÁdUA CARRIERI ${ }^{1}$
}

${ }^{1}$ Universidade Federal de Minas Gerais (UFMG), BELO Horizonte - MG, BRASIL

\section{Resumo}

Análise da construção das identidades de prostitutas evangélicas que trabalham em uma zona do "baixo meretrício" da cidade de Belo Horizonte, Minas Gerais. Para tanto, desenvolveu-se um estudo exploratório de abordagem qualitativa com entrevistas em profundidade com 17 prostitutas evangélicas, cujo corpus discursivo foi trabalhado mediante a proposta teórico-metodológica da Análise Linguística do Discurso. Dentre os principais resultados alcançados, destacam-se um profundo sentimento de culpa e, em alguns casos, dor e sofrimento das prostitutas evangélicas, dado o paradoxo de comungar de valores e crenças pessoais intrinsecamente opostas às práticas de seu ofício. Contudo, questões mais objetivas, como o sustento e a manutenção própria e da família, levaram-nas a se sujeitarem a esta realidade.

Palavras-chave: Prostitutas. Evangélicas. Identidades. Estigma.

Between the sacred and the profane: identities, paradoxes, and ambivalences of evangelical prostitutes from a red-light district of Belo Horizonte

\begin{abstract}
This study aimed to analyze the construction of the identities of evangelical prostitutes who work in a red-light district (zona do baixo meretrício) of the Brazilian city of Belo Horizonte, Minas Gerais. It is an exploratory and qualitative study, using in-depth interviews with 17 evangelical prostitutes, analyzed through the theoretical-methodological proposal of the linguistic discourse analysis. Among the main results, we highlight a deep sense of guilt and, in some cases, pain and suffering of evangelical prostitutes, given the paradoxicality of commune personal values and beliefs intrinsically opposed to the practices of their work. However, more objective questions, such as support themselves and their family, led them to this reality.
\end{abstract}

Keywords: Prostitutes. Evangelicals. Identities. Stigma.

Entre lo sagrado y lo profano: identidades, paradojas y ambivalencias de prostitutas evangélicas del bajo meretricio de Belo Horizonte

\section{Resumen}

El objetivo de este estudio es analizar la construcción de las identidades de prostitutas evangélicas que trabajan en una zona del "bajo meretricio" de la ciudad de Belo Horizonte, Minas Gerais. Para ello, se desarrolló un estudio exploratorio de abordaje cualitativo con entrevistas en profundidad con 17 prostitutas evangélicas, en las que el corpus discursivo se trabajó mediante la propuesta teórico-metodológica del análisis lingüístico del discurso. Entre los principales resultados, destacamos un profundo sentimiento de culpa y, en algunos casos, dolor y sufrimiento de las prostitutas evangélicas, dada la paradoja de comulgar con valores y creencias personales intrínsecamente opuestas a las prácticas de su oficio. Sin embargo, cuestiones más objetivas, como el sustento y el mantenimiento propio y de la familia hizo que ellas se sujetaran a esta realidad.

Palabras clave: Prostitutas. Evangélicas. Identidades. Estigma. 


\section{INTRODUÇÃO}

A prostituição é versada como uma atividade humana milenar conhecida popularmente como a "profissão mais antiga do mundo" (BARRETO, 2013). O primeiro relato sobre este ofício é narrado na Bíblia, trata-se da história de Maria Madalena, a prostituta mais famosa do mundo (BASSERMANN, 1994). Há relatos de que, nas primeiras civilizações mesopotâmicas e egípcias, a figura da prostituta era envolta por um caráter sacro, sendo, em alguns momentos, vinculada a divindades e, por conseguinte, com grande influência social nas esferas econômica, política e religiosa. Tal imagem passou a ser contestada a partir do declínio do Império Romano, quando se começa a propagar a ideia de que a prostituição era um ato moralmente repreensível, que traria corrupção ao resto da sociedade (SACRAMENTO e RIBEIRO, 2014).

Este momento histórico marca o prelúdio dos processos de desmoralização e estigmatização da mulher-prostituta e do seu trabalho, que decai de um lugar de divindade e passa à escória da sociedade. Logo, a imagem sacra passa a ser demonizada. A esses "seres errantes" é atribuída uma pecha de pecado pelo fato de realizarem uma atividade socialmente estereotipada como indigna, humilhante, suja, pesada e desprestigiada (FANGANIELLO, 2008). Como reflexo disso, a prostituição incorpora o estigma de "trabalho sujo" (HUGHES, 1958; ASHFORTH e KREINER, 1999).

Nos dias atuais, o imaginário em torno da prostituição é múltiplo, assim como também são diversos os juízos morais e preconceitos que o acompanham. "Cultuada, perseguida, redimida de seus pecados, a prostituta se torna alguém não trivial, permeada pelo exotismo e pela sacralidade do tabu sexual que a engloba" (LOPES, 2017, p. 37). Notavelmente, a imagem da prostituta é relacionada à depravação sexual, afinal "[...] a própria definição de prostituição é indicativa dessa visão, sendo compreendida como relações sexuais antinaturais e/ou moralmente condenáveis, como adultério, concubinato e poligamia" (BARRETO, 2013, p. 75). Desse modo, a identidade social da prostituta associa-se ao fato de ela manter relações sexuais com inúmeros homens, sem finalidade de procriação, contrariando as regras de honestidade e moralidade socialmente estabelecidas, que, no cenário brasileiro, são fortemente influenciadas por preceitos religiosos (CUNHA, 2014). Segundo a visão religiosa focalizada neste estudo, pautada em dogmas cristãos-evangélicos, as causas da prostituição seriam traumas e abusos sexuais na infância, cuja "cura" implicaria força de vontade, assim como ocorre entre os viciados em substâncias psicoativas (MARIZ, 2016).

A esses indivíduos é apregoada uma religiosidade balizada nas premissas de que: "o corpo é templo do Espírito Santo", portanto não pode ser profanado pela prostituição; precisariam se valorizar enquanto seres humanos e filhos de Deus; poderiam possuir qualquer outro "trabalho comum"; deveriam se arrepender e pedir perdão a Deus por terem "vendido seu corpo" (pecado grave na doutrina evangélica). Visando aprofundar nas formas religiosas e morais de se conceber a prostituição, recorre-se, neste estudo, a algumas referências bíblicas. Em Deuteronômio (23:17-18), a prostituta é chamada de "abominação ao Senhor", em Apocalipse (17:1-3) ela é associada à figura de uma besta que levou o mundo à perdição, "[...] mostrar-te-ei a condenação da grande prostituta que está assentada sobre muitas águas; com a qual fornicaram os reis da terra; e os que habitam na terra se embebedaram com o vinho da sua fornicação". Esses ensinamentos, portanto, são utilizados como respaldo pelas religiões de matriz (neo)pentecostal para outorgar a prostituta convertida, em processo de conversão, ou mesmo aquela que pode ser objeto de conversão.

Na doutrina evangélica o sexo fora do casamento é considerado pecado, dado que tal ato comporia os domínios das seduções diabólicas. A igreja evangélica atribui valor e reveste de sentido positivo o abandono desta prática, considerada pela religião como abominável (LOPES, 2017), uma vez que, conforme pregação nos cultos, após a conversão, o ser humano torna-se templo do Espírito Santo. Inspirado pela percepção de que "Deus escolhe o seu povo para que seja crente e santo. [...] Você pode aproximar-se de Jesus Cristo como um pecador, mas não pode aproximar-se d'Ele como uma pessoa eleita enquanto sua santidade não for visível" (SPURGEON, 1996, p. 25), o indivíduo deixa então essa condição degradada de pessoa, submetida às forças do mal, e emerge como "salva pelo Evangelho" (BIRMAN, 2009). Sendo assim, a "ex-prostituta", convertida ou em processo de conversão, inicia um processo de ressignificação e reposicionamento de vida e torna-se testemunho da bênção de Deus, da forma "como Deus age" na vida das pessoas (BIRMAN, 2009; LOPES, 2017). Nesse aspecto, é contraditório e religiosamente considerado um choque de princípios a prostituta "convertida ao Evangelho" manter a mesma vida e hábitos profissionais "pecaminosos".

Importante considerarmos ainda que, indissociável de um tempo histórico, o estigma apregoado sobre a prostituta pode ser compreendido como um "[...] processo relacional, circunscrito no tempo e no espaço, pelo qual um grupo de atores projetou em outro grupo de personagens certos atributos que Ihe conferiram marginalidade e justificaram o seu exílio do tecido social" 
Entre o sagrado e o profano: identidades, paradoxos e ambivalências de prostitutas evangélicas do baixo meretrício de Belo Horizonte
Jefferson Rodrigues Pereira | José Vitor Palhares dos Santos Alice Gerlane Cardoso da Silva | Kely Cesar Martins de Paiva Alexandre de Pádua Carrieri

(BASTOS, 1997, p. 14). Trata-se, portanto, de um atributo que não se enquadra nos padrões e normas sociais que regulam os processos de construção de identidades (GOFFMAN, 1982). Desse modo, essa divergência serve como móbil para depreciar a identidade e macular seu status enquanto indivíduo, mesmo que seu ofício não se configure ilícito penalmente, como o caso da prostituição no Brasil. Em termos agregados, "a prostituta é estigmatizada não por cometer qualquer infração legal, mas pela sua divergência face aos valores dominantes que regulam a sexualidade feminina e estabelecem uma ideia moral de ordem" (SACRAMENTO e RIBEIRO, 2014, p. 200). A influência de padrões e valores religiosos ditam o que é certo ou errado e/ou moral ou imoral na sociedade atual (LOPES, 2017).

Os estudos sobre prostituição na Administração e especificamente nos Estudos Organizacionais não são recentes e estão associados a categorias teóricas tais como sentido do trabalho (SILVA e CAPPELLE, 2015; SILVA e CAPPELLE, 2017a), carreiras (BREWIS e LINSTEAD, 2000), trabalho sujo e estigmas (BLITHE e WOLFE, 2017), regulação e (des)criminalização do trabalho (WEST, 2000; WAGENAAR, 2006), dentre outras, e que direcionam, portanto, o desenvolvimento deste estudo. Já o processo de construção identitária de prostitutas, foco desta pesquisa, apesar de também ter ganhado destaque na área nos últimos anos (PEREIRA, PAIVA, SANTOS et al., 2018; SANDERS, 2005), ainda necessita de novas teorizações, visto que é um tema marginal nos Estudos Organizacionais devido ao fato de que a prostituição ainda não é reconhecida socialmente como profissão, consequentemente seu mercado e tudo que o envolve são afastados dos estudos sobre gestão (SILVA e CAPPELLE, 2017b).

Procurando preencher essa lacuna de pesquisa e tendo em vista que é uma profissão socialmente estigmatizada, o presente artigo tem como objetivo analisar a construção de identidades de prostitutas evangélicas que trabalham em uma zona do "baixo meretrício" da cidade de Belo Horizonte, Minas Gerais. Neste estudo, entende-se por construção identitária o processo de construção de si mesmo mediante processos de identificação (ALVESSON e WILLMOTT, 2002) e de (re)construção identitária pelas relações sociais estabelecidas com os outros e pelos sentidos subjetivos que se atribuem ao trabalho.

Desse modo, a contribuição com esta pesquisa se dá em duas vertentes. A primeira está relacionada ao aprofundamento e avanço nas discussões teóricas sobre a construção identitária de um grupo específico de profissionais que é marginalizado nos estudos sobre gestão (SILVA e CAPPELLE, 2017b), isto é, o de prostitutas. Além disso, este estudo se diferencia teoricamente por utilizar um viés original pela via da religiosidade, uma vez que esse tema também é pouco explorado e debatido nos Estudos Organizacionais (TRACEY, 2012; GUNDOLF e FILSER, 2013; CARNEIRO, SERAFIM e TEZZA, 2018), especialmente quando se trata de prostitutas evangélicas. Não menos importante, este trabalho também tem sua contribuição social ao ouvir sujeitas estigmatizadas e marginalizadas e fazer suas vozes e anseios chegarem a outras instâncias, buscando tirá-las da invisibilidade social na qual estão insculpidas.

\section{Religião, Moral e Trabalhos Sexuais}

Ainda que diversos sociólogos clássicos, como Durkheim (1996) e Weber (1967), tenham realizado o debate em torno da religião e de sua influência nos modos de existência dos indivíduos, somente nas últimas décadas é que tal temática tem sido discutida nos estudos de gestão (GUNDOLF e FILSER, 2013). O conceito de religião pode ser compreendido como um sistema de símbolos que constrói e é construído socialmente, que transcende e inclui o ser humano, sendo privilegiado por legitimação, conservação da ordem e manutenção do status quo (BERGER, 1985). O processo de legitimação das instituições religiosas exprime a necessidade de utilizar instrumentos para que uma realidade socialmente definida seja perpetuada, a fim de que a ideia de real seja assimilada pelos seus integrantes como dado, evidente por si mesmo. Notavelmente, ao longo da história, a educação religiosa sempre foi reprodutora e condicionante de padrões socialmente aceitos, sendo a linguagem religiosa (repetições à exaustão dos dogmas) um meio importante e necessário para a o fortalecimento e manutenção de sua identidade (CAMPOS e MARIANI, 2015).

Desse modo, pode-se dizer que religião e moralidade relacionam-se intrinsecamente, uma vez que uma das funções da religião é tornar sensível uma disposição moral por meio da ideia de Deus. A moralidade cristã, entendida aqui como um conjunto de valores cristãos socialmente compartilhados, avalia ações humanas e modos de vida como certos ou errados e classifica as pessoas em boas e ruins. Assim, valores morais podem proporcionar a capacidade de autoavaliação e avaliação dos outros, possibilitando, consequentemente, comparações distintivas e hierarquizantes sobre o modo como nos comportamos em relação a nós mesmos e aos outros (TAYLOR, 1997).

Tais avaliações morais também recaem sobre o trabalho, tendo em vista que cada profissão é valorizada de forma diferente, sob acordos morais sutis e hierarquizantes entre mente e corpo: trabalhos que se utilizam mais do corpo que da mente são 
Entre o sagrado e o profano: identidades, paradoxos e ambivalências de prostitutas evangélicas do baixo meretrício de Belo Horizonte
Jefferson Rodrigues Pereira | José Vitor Palhares dos Santos Alice Gerlane Cardoso da Silva | Kely Cesar Martins de Paiva Alexandre de Pádua Carrieri

desvalorizados moralmente, considerados degradantes e menos dignos (HONNETH, 2008). Já a religião pode fazer transcender o caráter instrumental das pessoas no trabalho e aumentar a compreensão sobre a complexidade e individualidade dos sujeitos (SILVA e SIQUEIRA, 2009). Além disso, a religião permitiria ao trabalhador a geração de um conjunto de atitudes de enfrentamento do sofrimento no trabalho (PAIVA, 1998), bem como seria fonte de aumento de sentido e prazer (SILVA e SIQUEIRA, 2009), satisfação, eficiência e criatividade no ambiente laboral (MITROFF e DENTON, 1999).

A religião pode ser compreendida como provedora de sentido à vida, como capacidade de responder ao sofrimento, à morte e à miséria, como apoio, refúgio e sustento psicológico, prometendo aos fiéis a salvação e a libertação do sofrimento (MARIANO, 1999). Nesse aspecto, “[...] somente a tradição religiosa promete uma salvação para além de qualquer apocalipse e qualquer destruição das coisas. As sobrevivências, por sua vez, concernem apenas à imanência do tempo histórico: elas não têm nenhum valor de redenção" (DIDI-HUBERMAN, 2011, p. 84).

Assim, a religião permeia a transição entre humanização e precariedade do trabalho (DAVEL e VERGARA, 2001) e busca possibilitar que as pessoas reconectem-se ao mundo, ao transcendente, à sociedade (MOORE, 2004) e, consequentemente, ao trabalho. Entretanto, diversas religiões, principalmente as de matriz cristã, e a prostituição conviveram com um paradoxo em suas histórias. Ao mesmo tempo que condenava o trabalho sexual - até mesmo na figura popular de Maria Madalena, que teve sua redenção quando perdoada por Cristo (DABHOIWALA, 2013) -, a Igreja Católica sempre destacou a importância de a mulher resguardar sua virgindade ao casamento, fazendo uma alusão clara à Virgem Maria, coibindo qualquer desejo sexual que poderia surgir antes do matrimônio. Desse modo, a forma de remediar o desejo sexual dos homens - considerado, em uma sociedade patriarcal, de ordem das necessidades fisiológicas, já que eles poderiam adoecer gravemente em abstinência sexual (BOURDIEU, 1999) - foi “[...] junto às casas de meretrício onde eles podiam aliviar a sua libido, conter a sua 'loucura' sexual e resguardar a virgindade das filhas de Maria ao casamento" (MANAIA, 2011, p. 2681).

A conduta sexual surge como uma centralidade simbólica em diversas religiões. No cristianismo, por exemplo, há a ideia de que é possível uma purificação total da pessoa ainda na terra, quando o fiel consegue alcançar um estado sublime de santidade, mediante, dentre outras coisas, uma vida celibatária. A abstinência sexual é vista como um sinal privilegiado do sucesso do fiel sobre a carne e um controle perfeito de si (CARRARA, 2000). Além disso, enquanto matrizes morais, as religiões aparecem como orientadoras de construções de sentidos, e pessoas "hereges", "desviantes" ou com "condutas inadequadas" devem ser conscientizadas e/ou punidas, por apresentarem riscos à preservação da ordem do mundo e à segurança que a religião dispõe aos fiéis (CAMPOS e MARIANI, 2015). É nesse contexto que se situa a prostituta, considerada sinônimo de promiscuidade feminina, tendo seu trabalho e identidade condenados moralmente (LOPES, 2017).

Objeto de tentativa de conversão de muitos religiosos, as prostitutas que resolverem se converter e se tornar ex-prostitutas, em religiões como a evangélica, podem ter um fim diferente daquelas outras. Por meio da "discriminação positiva", a ex-prostituta poderá comprovar como é ruim estar do "outro lado" ao abandonar essa prática tão abominável entre os fiéis, ao passo que se atribuirá valor à sua história de vida após a "posse da palavra" (LOPES, 2017, p. 35). Dessa forma, algumas religiões surgem como fonte de salvação moral, ressignificação e reposicionamento da biografia dessas mulheres, tendo em vista a composição moral da prostituição enquanto trabalho no imaginário social.

\section{Sobre Identificações e Identidades}

A identidade tem sido apresentada como uma atribuição essencial ou um caráter central no indivíduo (CABANA e ICHIKAWA, 2017). Trata-se de um conceito amplo, complexo, usado correntemente para entender a interação do indivíduo com o mundo e sua relação com o outro (AVELAR e PAIVA, 2010). Dada sua importância, muito se tem discutido sobre o a identidade e como ela é construída (SOUZA e CARRIERI, 2012).

Berger e Luckmann (2011) compreendem a identidade como um fenômeno que advém da relação dialética entre um indivíduo e a sociedade. Constitui-se, assim, como um processo de interiorização, em que o sujeito é inserido no mundo objetivo de uma sociedade. A identidade é “[...] o resultado a um só tempo estável e provisório, individual e coletivo, subjetivo e objetivo, biográfico e estrutural, dos diversos processos de socialização que, conjuntamente, constroem os indivíduos e definem as instituições" (DUBAR, 2005, p. 136). Sendo assim, a identidade é um processo compreendido como as definições que as pessoas têm de si mesmas, sendo estabelecida por meio das relações com os outros, podendo sofrer alterações a depender das experiências vivenciadas pelos sujeitos em seu cotidiano. Deve-se considerar, portanto, as perspectivas pessoal e social ao se analisar o processo de construção identitária (SOUZA e CARRIERI, 2012). 
Entre o sagrado e o profano: identidades, paradoxos e ambivalências de prostitutas evangélicas do baixo meretrício de Belo Horizonte
Jefferson Rodrigues Pereira | José Vitor Palhares dos Santos Alice Gerlane Cardoso da Silva | Kely Cesar Martins de Paiva Alexandre de Pádua Carrieri

Assim, a perspectiva da identidade que ora é associada a algo individual, singular, permanente e uniforme, na conjuntura de "ser para si", tem se modificado para uma perspectiva dinâmica, de processo em constante construção e reconstrução (CAMPOS e OGUISSO, 2008; AVELAR e PAIVA, 2010), cujas experiências individuais de socialização compõem seu principal elemento de formação (MACHADO, 2003; BERGER e LUCKMANN, 2011). As teorias que retratam a temática reconhecem que a identidade não é fixa e nunca está totalmente finalizada, trata-se de um processo social e passa por transformações durante toda a vida, sob a influência dos diversos contextos, sejam eles históricos, sociais, regionais e/ou culturais (BOULART e LANZA, 2007). A construção da própria identidade mantém-se como um desafio permanente para o indivíduo, no sentido de encontrar aquilo que ele é e o que os outros esperam que ele seja. Nesse processo, o outro acaba sendo uma espécie de espelho social que consente ao sujeito reconhecer-se, analisar-se e aprovar-se (WHETTEN e GODFREY, 1998). Nesse sentido, Boulart e Lanza, $(2007$, p. 8) ressaltam que a "[...] identidade pessoal sempre busca equilíbrio entre aquilo que o sujeito é e o que os demais esperam que ele seja".

Notavelmente, tal perspectiva imprime ambiguidades e imprecisões quanto ao termo identidade, muitas vezes utilizado com sentido de identificação (FERNANDES, 2009; ROQUETE, BRITO, MELO et al., 2012). Identidade refere-se à "[...] auto definição do sujeito, na interação entre o eu e a sociedade, entre o interior e o exterior; a identificação, por sua vez, diz respeito à obtenção pelo sujeito das qualidades do outro, no sentido de elevar a sua autoestima" (FERNANDES, 2009, p. 2). A identidade se fragmenta entre "o que eu sou" e "o que acham que eu sou"; entre a concepção que tenho do meu eu e a que os outros têm do meu eu (DUBAR, 2005), assim, na medida em que o indivíduo é identificado, ele se identifica (SOUZA e CARRIERI, 2012). Nessa perspectiva, o termo identidade debruça-se sobre "quem sou eu?", e o termo identificação sobre "[...] como sei quem sou em relação a você?" (FERNANDES, 2009).

Desse modo, embora cada indivíduo porte um senso de individualidade, a constituição do autoconceito é fundamentada na percepção dos outros sujeitos, ou seja, precisa do reconhecimento e da legitimação dos outros indivíduos que integram a sua realidade social (MACHADO, 2003; MONTEIRO, PEREIRA, OLIVEIRA et al., 2017). Assim, a identidade apresenta-se como o resultado de diversas identificações (MIRANDA, 1998). Diante disso, o estudo da identidade envolve várias perspectivas ou níveis de análise, que, apesar de distintas, se complementam (MACHADO, 2003; AVELAR e PAIVA, 2010). Em termos gerais, a literatura menciona dois níveis sobre essa temática: o pessoal e o social (CASTELLS, 1999; HOWARD, 2000; MACHADO, 2003; AVELAR e PAIVA, 2010), sendo esta, portanto, a classificação mais recorrente para especificar o fenômeno em seus níveis de percepção (MACHADO, 2003).

A identidade pessoal compreende a construção individual do "conceito de si mesmo", ou do "autoconceito" por meio de relações sociais, e acontece em todas as etapas da vida do indivíduo. Já a identidade social se refere à construção do conceito de si mediante o vínculo do indivíduo a um ou vários grupos sociais e pode direcioná-lo e legitimá-lo, refletindo a ação grupal (AVELAR e PAIVA, 2010). Esse processo, portanto, é gerado por conformidade, de acordo com os diferentes grupos aos quais o indivíduo pertence, mas, também por oposição, perante os grupos aos quais ele não pertence (MACHADO, 2003).

Para os propósitos deste artigo é importante considerar o impacto do trabalho na formação das identidades (MACHADO, 2003; DUBAR, 2005), uma vez que a socialização dos sujeitos no mundo do trabalho possibilita a construção de uma identidade no trabalho baseada nas experiências vivenciadas no universo produtivo, as quais acarretam relações de poder e regras coletivas de comportamento (MACHADO, 2003). A identidade no trabalho é entendida como "[...] uma construção do eu pela atividade que o indivíduo realiza e pelas pessoas com quem se relaciona no trabalho" (AVELAR e PAIVA, 2010, p. 1011).

Algumas atividades laborais são socialmente marginalizadas, assumindo o estigma de "trabalho sujo", ou seja, "[...] tarefas fisicamente asquerosas ou que simbolizam algo degradante ou humilhante" (HUGHES, 1958, p. 81), que, por vezes, estigmatizam e aviltam os indivíduos que as realizam (BORGES e MOURÃO, 2013). O termo "trabalho sujo" é utilizado para descrever tal situação de várias formas: física, social e/ou moralmente repugnante (ASHFORTH e KREINER, 1999; SOUTHGATE e SHYING, 2014), influenciando, consequentemente, a construção identitária do sujeito (BROWN, 2015).

Diante do exposto, é relevante salientar as noções de estigma e moralidade, bem como suas respectivas influências nos processos de identificação e construção identitária. A ideia de estigma é reflexo de um processo relacional, por meio do qual determinados grupos carregam "manchas" depreciativas por seus padrões comportamentais e de existência serem opostos ao socialmente tido como certo, sendo chamados "comportamentos desviantes" (BASTOS, 1997). O estigma refere-se a um atributo que não se adéqua às expectativas normativas que determinam as construções identitárias e a definição das ações sociais (GOFFMAN, 1982). Assim, todos aqueles que apresentam singularidades contrárias ao sistema dominante de normas 
Entre o sagrado e o profano: identidades, paradoxos e ambivalências de prostitutas evangélicas do baixo meretrício de Belo Horizonte
Jefferson Rodrigues Pereira | José Vitor Palhares dos Santos

Alice Gerlane Cardoso da Silva | Kely Cesar Martins de Paiva Alexandre de Pádua Carrieri

e valores são, simbolicamente, declarados como alvos de impureza e poluição social (RIBEIRO, SILVA, SCHOUTEN et al., 2007). A noção de moralidade, por sua vez, deve ser considerada pela observância de que "quem nós éramos, somos e estamos nos tornando são questões fundamentalmente morais" (BROWN, 2015, p. 33), aspecto importante, principalmente, por se tratar, aqui, de estudo sobre prostitutas do baixo meretrício adeptas da religião evangélica.

\section{PROCEDIMENTOS METODOLÓGICOS}

Para atingir o objetivo proposto, realizou-se uma pesquisa exploratória, de abordagem qualitativa. Os dados foram coletados por meio de entrevistas em profundidade com dezessete prostitutas que atualmente trabalham em uma zona de prostituição do baixo meretrício em Belo Horizonte e que seguem a religião evangélica. É importante ressaltar que as entrevistas foram realizadas in loco, no local e no horário de trabalho das prostitutas, as quais puderam ser encontradas pelo critério de acessibilidade.

As entrevistadas deste estudo trabalham na região central da cidade de Belo Horizonte (MG), Zona da Guaicurus, região conhecida nacionalmente pela prostituição e imortalizada pelo romance Hilda Furacão, do escritor Roberto Drummond (1991). Para os fins deste estudo, inicialmente foram realizadas três visitas aos bordéis com o objetivo de conhecer melhor a dinâmica do espaço. Nessas visitas, recorreu-se a diários de campo nos quais foram registradas diversas observações e vivências no ambiente, como recomenda a literatura (ANGROSINO, 2009). Tal fato contribuiu sistematicamente para a compreensão de aspectos cotidianos das participantes do estudo.

Importante ressaltar que a realização das entrevistas teve início a partir da quarta visita aos bordéis. A coleta de dados foi realizada entre os meses de maio e dezembro de 2017, com média de uma a duas abordagens por semana. Ao final, dezoito diferentes bordéis da região central da capital mineira foram visitados, houve explicação sobre o objetivo do estudo e proposta de participação na pesquisa. Somente depois da obtenção dos Termos de Consentimento Livre e Esclarecido (TCLE) assinados pelas entrevistadas, as entrevistas se iniciaram. Importante esclarecer que, tendo em vista tratar-se de estudo que se encaixa em prerrogativas de incisos do parágrafo único do Art. 10 da Resolução 510/2016 (BRASIL, 2016), que reza sobre pesquisa com seres humanos nas ciências sociais e humanas, este projeto não foi submetido a comitê de ética em pesquisa; as demais recomendações da legislação foram cumpridas (assinatura de TCLE, guarda e manutenção dos dados etc.).

Optamos pela técnica da entrevista em profundidade, haja vista suas contribuições para os estudos acadêmicos, tais como facilitar o aceite por parte dos sujeitos entrevistados, aumentar o conforto entre os participantes e o entrevistador e melhorar a qualidade da pesquisa (DEVOTTA, WOODHALL-MELNIK, PEDERSEN et al., 2016).

Note-se, ainda, que este estudo está inserido em um projeto de pesquisa mais amplo - em andamento - nos bordéis da Guaicurus. Até a elaboração do recorte apresentado neste artigo, haviam sido entrevistadas 36 mulheres. Dentre estas, dezessete pertenciam à religião evangélica e passaram a constituir o corpus específico deste estudo. Sobre a produção de dados de campo, destacam-se, em primeiro lugar, questões relacionadas ao espaço físico, uma vez que nos corredores dos hotéis de prostituição é comum acontecerem pequenos furtos, vendas de aparelhos de celulares roubados, mesmo que proibidas pela gerência do hotel. Durante o processo de coleta foram oferecidos em três oportunidades celulares roubados a integrantes do grupo de pesquisadores. Configurou-se, assim, um espaço difícil para interagir com as prostitutas e explicar a proposta do estudo, considerando-se, principalmente, que adentrar os quartos só é possível mediante a aprovação das profissionais. Um segundo ponto importante de ser salientado relaciona-se às entrevistadas, visto que muitas delas mostravam-se resistentes à participação na pesquisa e as que aceitavam inicialmente mostravam-se arredias, o que mudava consideravelmente após os momentos iniciais de conversa na entrevista.

Ainda considerando aspectos éticos da pesquisa relacionados a sigilo de informantes, neste estudo, após aprovação das entrevistadas, elas foram identificadas pelo que denominam como "nome de guerra", ou seja, pseudônimos que utilizam com os clientes no cotidiano de trabalho. Além das entrevistas, o grupo de pesquisadores utilizou-se de diários de campo e de observações sistemáticas nos locais de trabalho (ANGROSINO, 2009). Todo esse material formou o corpus analítico da pesquisa, que possibilitou um melhor entendimento da profissão das sujeitas de pesquisa. Assim, foi possível apreender elementos importantes sobre o contexto das identidades, da vida, do trabalho e da religião das prostitutas. 
Entre o sagrado e o profano: identidades, paradoxos e ambivalências de prostitutas evangélicas do baixo meretrício de Belo Horizonte
Jefferson Rodrigues Pereira | José Vitor Palhares dos Santos Alice Gerlane Cardoso da Silva | Kely Cesar Martins de Paiva Alexandre de Pádua Carrieri

O material levantado e produzido em campo foi submetido a um tratamento sistemático dos dados, que se deu por meio da proposta teórico-metodológica da Análise Linguística do Discurso (ALD), a qual tem base nas articulações entre a área da Linguística, Filosofia e Ciências Sociais (ORLANDI, 2009) e que centra nas análises do simbólico que produz sentido e está investido de significância para e por sujeitos (PÊCHEUX, 2014). Essa proposta de análise permite que sejam examinados os efeitos construtivos relativos a linguagem, processos de produção, distribuição e consumo de textos, possibilitando uma análise reflexiva e interpretativa que visa compreender o papel do discurso em uma realidade socialmente construída (FAIRHURST e COOREN, 2018). Ademais, a ALD atualmente tem sido bastante utilizada nas pesquisas brasileiras em Estudos Organizacionais (FARIA, 2015), bem como em estudos estrangeiros da área (ALVESSON e KÄRREMAN, 2011). Foram identificados quatro percursos semânticos na construção identitária de prostitutas evangélicas, os quais nortearam a apresentação e análise de dados, a saber: o discurso da necessidade e centralidade do trabalho para a sobrevivência dessas profissionais; a organização das múltiplas identidades; dilemas e contradições cotidianas; e estratégias de resistência desenvolvidas em virtude das contradições do trabalho sujo.

\section{ANÁLISE DE RESULTADOS E DISCUSSÕES}

Inicialmente, destaca-se que as participantes deste estudo se auto definem como cristãs que seguem uma doutrinação evangélica. Das entrevistadas, seis participavam regularmente de cultos da Igreja Batista; quatro, da Universal do Reino de Deus; três, da Assembleia de Deus; três, da Deus é Amor; e uma, da Igreja Internacional da Graça de Deus. Quanto à faixa etária, possuíam entre 19 e 63 anos. No que se refere ao grau de escolarização, treze possuíam ensino médio completo; três, ensino fundamental incompleto e uma cursava nível superior.

A maioria das mulheres entrevistadas neste estudo possuía filhos (treze delas), declarou-se solteira, divorciada ou viúva. Importante destacar ainda que das entrevistadas para este estudo, apenas três eram naturais de cidades de Minas Gerais, as outras catorze vinham de cidades de outros estados brasileiros e justificavam a escolha pela Zona da Guaicurus por sua fama e pelo fato de fazerem muitos programas diários (o que compensa o baixo preço cobrado) (PEREIRA, PAIVA, SANTOS et al., 2018). O valor médio do programa comum (sem penetração anal, acessórios e/ou fantasias) fica entre 10 a 25 reais, ao passo que o número de programas realizados diariamente por cada entrevistada fica entre 30 a 35, em dias convencionais. Todas as entrevistadas afirmam que, próximo ao quinto dia útil do mês, a quantidade de programas que realizam diariamente aumenta para, em média, 55 programas, podendo atingir até oitenta programas diários.

\section{Trabalho, religiosidade, identidades e estigmas}

Quando se propõe uma discussão acerca das relações que se estabelecem entre trabalho, religiosidade, identidades e estigmas de prostitutas evangélicas, vários paradoxos e ambivalências são facilmente percebidos. Intermináveis confrontos entre o sagrado e o profano, a moral e o trabalho, a espiritualidade e a sobrevivência, os padrões comportamentais socialmente aceitos e os comportamentos desviantes revelam a complexidade de tais relações.

Diante disso, é importante ratificar que a identidade da prostituta está atrelada a estigmas, valores morais e religiosos no contexto brasileiro, sendo a prostituição associada à promiscuidade, e a prostituta perseguida e taxada como um ser errante, uma vez que seu corpo não é resguardado ao Espírito Santo (LOPES, 2017). Passagens bíblicas corroboram essa afirmação. Em Ezequiel (16:32-34), por exemplo, as prostitutas são vistas como meretrizes, e suas "prostituições" deveriam ser punidas por apedrejamento, como acontece com mulheres adúlteras. Assim, as identidades de prostitutas evangélicas transitam entre aspectos do sagrado e do profano, dado que suas crenças e valores religiosos se chocam com suas práticas de trabalho, sublinhando a importância do mundo do trabalho e seu significado na construção de suas identidades (DUBAR, 2005).

Todas as entrevistas passaram pela centralidade do trabalho, associando-o, prioritariamente, à necessidade de sobrevivência própria e da família. O objetivo de trabalho é a garantia do sustento pessoal e familiar, mas torna-se alvo de condenação ou negação. As trabalhadoras parecem contaminadas por um mesmo julgamento, a ponto de muitas se calarem ou esconderem sob ambiguidades as tentativas de uma apresentação que valorize seu trabalho (CANHOLI JÚNIOR, LIMA, LIMA et al., 2016).

Todas as entrevistadas declararam estar cientes de que seu trabalho "não é agradável aos olhos de Deus", entretanto, questões materiais, tais como sustentar o pai, netos ou pagar fiança para um filho sair da cadeia, justificam o comportamento desviante 
Entre o sagrado e o profano: identidades, paradoxos e ambivalências de prostitutas evangélicas do baixo meretrício de Belo Horizonte
Jefferson Rodrigues Pereira | José Vitor Palhares dos Santos Alice Gerlane Cardoso da Silva | Kely Cesar Martins de Paiva Alexandre de Pádua Carrieri

(STARK e BAINBRIDGE, 2013). O não ser considerado "agradável aos olhos de Deus" revela uma das funções da religião de tornar sensível uma disposição moral, por meio da ideia de Deus. Assim, o trabalho da prostituta, além de ser considerado menos (ou nada) digno e desvalorizado moralmente por utilizar mais o corpo que a mente (HONNETH, 2008), é objeto de comparações distintivas e hierarquizantes sobre o modo como nos comportamos em relação a nós mesmos e aos outros (TAYLOR, 1997), por um conjunto de valores cristãos socialmente compartilhados que classificamos como errantes e/ou ruins.

O processo de construção identitária passa por uma ótica discursiva e interativa (DOWN e REVELEY, 2009), por isso é possível entender as identidades fragmentadas e multifacetadas das prostitutas evangélicas, manifestas na autoconsciência de que transgridem as normas religiosas que norteiam suas crenças. Isto, associado ao estigma da profissão, dá origem a um processo de fragmentação que cria uma identidade deteriorada (GOFFMAN, 1959), tanto de sua própria perspectiva quanto da perspectiva da sociedade.

Eu me sinto muito mal, tenho até vergonha de encarar meus pais nos olhos, mesmo sabendo que sou eu que sustento minha família, porque isso aqui não é trabalho, é falta de vergonha (Samara).

A sociedade vê a Guaicurus como uma mancha negra, como o pior dos mundos, inclusive aqueles que nos frequentam (Michele).

É importante sublinhar o interdiscurso da prostituição como uma nódoa associada ao trabalho. Segundo a definição de "trabalho sujo" (HUGHES, 1958), a atividade desempenhada pode "sujar" e "manchar" o indivíduo fisicamente, socialmente e moralmente. Baseando-se nas tipologias de manchas do trabalho sujo (ASHFORTH e KREINER, 1999), a prostituição seria manchada sob uma vertente social - que as tornam invisíveis socialmente - e moral - que as aviltam enquanto indivíduos. Note-se que "[...] dificilmente regras forjadas há séculos sob alicerces religiosos, morais, políticos e filosóficos cederão espaço à perspectiva de a prostituição ser entendida como uma atividade de trabalho como outra qualquer" (BARROS, 2005, p. 12). E, por apresentarem singularidades contrárias ao sistema dominante de normas e valores, as prostitutas são, simbolicamente, declaradas como alvo de impureza e poluição social (RIBEIRO, SILVA, SCHOUTEN et al., 2007).

Um tema recorrente nas entrevistas refere-se à função que a prostituta assume em uma sociedade patriarcal pautada por valores morais e religiosos. Alguns trechos discursivos asseveram a importância de a prostituta atender aos desejos masculinos, resguardando em casa a intocável mulher, casta e de reputação ilibada.

A gente costuma ouvir de homem que vem aqui assim: "minha esposa é uma mulher da igreja, é sagrada, e eu também sou. Minha mulher não pode nem ficar de quatro, vai contra os princípios da nossa igreja" ...como se eu também não fosse (Malu).

Relatos dessa natureza lançam luz em importantes contradições presentes na sociedade brasileira, em especial a ambiguidade entre pureza e impureza, sendo a primeira associada à abstinência sexual, dividindo as mulheres em duas grandes categorias: as esposas mães e alicerces da família, para quem o sexo é pecado se não for para a procriação-e as "outras", desviantes, que precisam existir para preservar a virgindade das futuras mães e ao mesmo tempo para satisfazer os "apetites sexuais" dos "honestos" senhores casados, "pais de família" (LEITE, 1986). Surge a discussão do "mal necessário", já que as prostitutas serviriam à liberdade sexual dos homens (LOPES, 2017) e à manutenção da castidade das "mulheres de família", "as filhas de Maria" (MANAIA, 2011)

Em relação ao percurso semântico dos dilemas e contradições vivenciados cotidianamente pelas prostitutas evangélicas, ressalta-se o confronto entre valores religiosos e práticas de trabalho - nos vários dilemas que refletem o paradoxo entre sagrado e profano. Por um lado, elas condenam o próprio trabalho em virtude da pecha de pecado.

Eu sei que estou errada, é um pecado mortal, Deus não agrada disso (Ana).

Por outro lado, elas ressaltam a importância desse trabalho para a sua sobrevivência e a de seus familiares, apelando à fé na tentativa de atrair mais clientes.

Eu sei que me prostituir é errado, que não agrada ao meu Senhor, mas todos os dias, em minhas orações, peço a Ele que me perdoe e abençoe meu dia de trabalho e me traga mais clientes. [...] Eu preciso tirar meu filho da cadeia, é uma questão muito importante para mim. Sei que estou assinando minha condenação, mas estou salvando meu filho. Mesmo no inferno acho que ficaria mais tranquila sabendo disso (Gi). 
Outro dilema que emerge na análise da construção identitária diz respeito ao interdiscurso do dinheiro "sujo" vindo desse trabalho. Há uma ideia difundida entre a maioria das entrevistadas de que o dinheiro ganho não é considerado honesto e justo, por não ser fruto de um trabalho "comum", aceito socialmente. O dinheiro da prostituta é sujo e amaldiçoado, porque os homens deixam de gastar com suas famílias para gastar com elas (LOPES, 2017). Essa perspectiva é reforçada em passagens bíblicas, como em Deuteronômio (23:18): “[...] não trarás o salário da prostituta nem o aluguel do sodomita para a casa do Senhor teu Deus por qualquer voto, porque uma e outra coisa são igualmente abomináveis ao Senhor teu Deus". Contra esse argumento, uma das entrevistadas questiona o porquê da desvalorização de seu dinheiro, negando a existência de uma contradição em doá-lo para a igreja (em forma de dízimo e ofertas) em virtude da sua profissão.

Porque meu dinheiro é mais sujo do que o do meu pastor que vem aqui me comer [gíria utilizada para referir-se ao ato sexual]? (Patrícia).

Este trecho discursivo escancara a hipocrisia presente na sociedade. O discurso moralista, pautado em dogmas religiosos (discurso religioso que condena a prostituição), convive com as práticas veladas contrárias a ele (pastores que se deitam luxuriosamente com as "abominações do Senhor"). O paradoxo insinua a sociedade androcêntrica e machista, na qual as mulheres são humilhadas ao bel-prazer de eventuais algozes.

Outro dilema corriqueiro das prostitutas evangélicas se refere à importância do Livro Sagrado e sua localização no momento da prestação de serviço profissional. No quarto de uma das entrevistadas, a Bíblia permanece em evidência assim como as ferramentas de trabalho - o livro fica aberto na parte de cima de um criado-mudo, ao lado da cama, já vibradores ficam na parte de baixo mais ao fundo. Outra entrevistada, ainda que mantenha a Bíblia em seu quarto, só presta seus serviços se ela estiver fechada - de seu ponto de vista, do contrário o ato se configuraria como pecado.

Já o percurso semântico das estratégias utilizadas pelas prostitutas para dar conta dos dilemas e contradições do trabalho sujo revela diversas alternativas criadas por essas profissionais em seu cotidiano na tentativa de reduzir a imoralidade e a culpabilidade que as afligem. Há quem tenha um espaço reservado no quarto para orações. Ali não acontece nada relacionado à prostituição. Trata-se de um lugar de penitência e oração diárias. Nesse sentido, a religião permite à prostituta a geração de um conjunto de atitudes de enfrentamento do sofrimento no trabalho (PAIVA, 1998). Outras dizem esforçarem-se para tratar a prostituição como um negócio qualquer, caracterizando o processo de mudança do self do estigmatizado na tentativa de alinhar-se às normas sociais (GOFFMAN, 1959). Em casos mais extremos, há aquelas que sentem necessidade de medicação antidepressiva e que, por vezes, se automutilam em crises existenciais e de culpa (Figura 1).

Figura 1

Mutilações

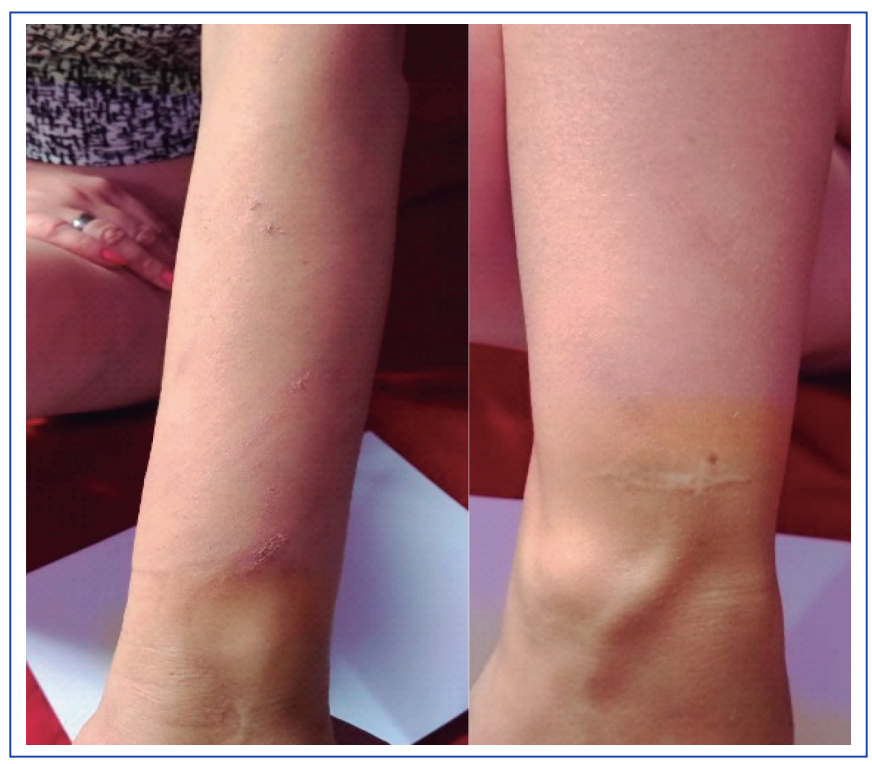

Fonte: Foto tirada pelos autores (2017). 
Entre o sagrado e o profano: identidades, paradoxos e ambivalências de prostitutas evangélicas do baixo meretrício de Belo Horizonte
Jefferson Rodrigues Pereira | José Vitor Palhares dos Santos Alice Gerlane Cardoso da Silva | Kely Cesar Martins de Paiva Alexandre de Pádua Carrieri

As mutilações parecem funcionar como mantenedoras de identidades questionadas por elas mesmas, que precisam se machucar, deixar cicatrizes visíveis no corpo punível e punido periodicamente como que para purgar o pecado, verem-se livre dele, purificarem-se mesmo que temporariamente, isto é, pelo tempo suficiente para justificarem a si mesmas, bem como a seu trabalho, e nele permanecerem.

É interessante ressaltar que, diferentemente da maioria das profissionais que prestavam seus serviços e que se encontravam despidas nos bordéis, as prostitutas entrevistadas neste estudo não se apresentavam assim, sob a justificativa de se distanciarem do estigma da mulher vagabunda e promíscua. Note-se que a socialização da prostituta no mundo do trabalho possibilita a construção de uma identidade no trabalho baseada nas experiências vivenciadas no universo produtivo, que acarretam relações de poder e regras coletivas de comportamento (MACHADO, 2003). Tais apontamentos reafirmam a estreita relação entre a formação identitária e a possibilidade de ocultar seu estigma, exposta por Goffman (1959), fato que tende a aumentar a pressão psicológica sobre o trabalhador, podendo decorrer daí problemas físicos, psíquicos e de socialização.

À luz dessas reflexões, é pertinente observar que, no caso das prostitutas evangélicas brasileiras, o estigma da imoralidade de seu trabalho impacta diretamente em sua representação de si (BROWN, 2015). Os discursos das prostitutas estão imersos num profundo sentimento de vazio e perda. Sofrem vergonha, culpa e sentimentos de inadequação, ou seja, quando as pessoas perdem confiança e autoestima, sua integridade moral se evapora (BROWN, 2015).

Olhos marejados, "nó na garganta", lágrimas, sentimento de culpa e vergonha foram recorrentes nas entrevistas realizadas, principalmente quando as entrevistadas discorriam sobre sua autoimagem, sua família e os paradoxos e ambivalências de seu trabalho, seus valores, suas crenças pessoais e sua relação com Deus. Estes são reflexos do processo fragmentado e multifacetado sobre o qual a identidade da prostituta evangélica se ergue. A representação do trabalho é construída no ambiente coletivo, daí surgem fissuras e contradições relacionadas à importância que o trabalho assume para as entrevistadas: de um lado, é fonte de sobrevivência (sendo esta sua principal importância, segundo as entrevistadas); de outro, fonte de sofrimento e vergonha, principalmente em razão do estigma nele refletido. Os estigmas que se perpetuam no cotidiano social fortalecem as mutilações simbólicas em vários níveis e a (re)construção do lugar "aceitável" dessas mulheres na sociedade.

Interessante o silenciamento do prazer no discurso de todas as entrevistadas. Nota-se a emersão de uma forte dimensão de sofrimento atrelada ao trabalho de prostitutas, uma questão paradoxal, considerando que elas trabalham diariamente com o prazer do outro. Tal fato corrobora e legitima a ideia da forçada representação econômica do trabalho, que se sobrepõe à "triste condição humana" (Malu). Portanto elas não são "tão errantes" quanto parecem. Fica evidente uma tentativa, por parte das entrevistadas, de construir suas identidades e significar sua autoimagem, de atenuar a mancha de seu "trabalho sujo" em prol da pureza, dignidade e moralidade. É importante salientar ainda a crença inabalável que todas as prostitutas entrevistadas possuem na misericórdia de Deus, e de que ainda lhes é possível a redenção e a salvação no "Juízo Final". Este sentimento de esperança pode inclusive fundamentar-se em passagens bíblicas:

Olha a minha maior esperança é que Jesus era constantemente criticado por andar com bêbados, prostitutas e homossexuais... E Ele sempre dizia: eu vim para estes (Gi).

Ao mesmo tempo que a religião emerge como fonte de hierarquização do que é trabalho digno e indigno, certo e errado, moralmente condenável (TAYLOR, 1997), paradoxalmente ela também se mostra provedora de sentido à vida, como capacidade de responder ao sofrimento, à morte e à miséria, como apoio, refúgio e sustento psicológico, prometendo aos fiéis a salvação e a libertação do sofrimento (MARIANO, 1999). Tal aspecto reforça as colocações de Didi-Huberman (2011, p. 84), de que "[...] somente a tradição religiosa promete uma salvação para além de qualquer apocalipse e qualquer destruição das coisas". A ideia de salvação encontra-se presente em diversos detalhes nos espaços de prostituição, como a porta do quarto de uma das entrevistadas, na qual estão estampados os dizeres "no final Jesus salva" no interior de um coração, escritos em batom vermelho (Figura 2). 
Entre o sagrado e o profano: identidades, paradoxos e ambivalências de prostitutas evangélicas do baixo meretrício de Belo Horizonte
Jefferson Rodrigues Pereira | José Vitor Palhares dos Santos

Alice Gerlane Cardoso da Silva | Kely Cesar Martins de Paiva Alexandre de Pádua Carrieri

Figura 2

\section{No final Jesus salva}

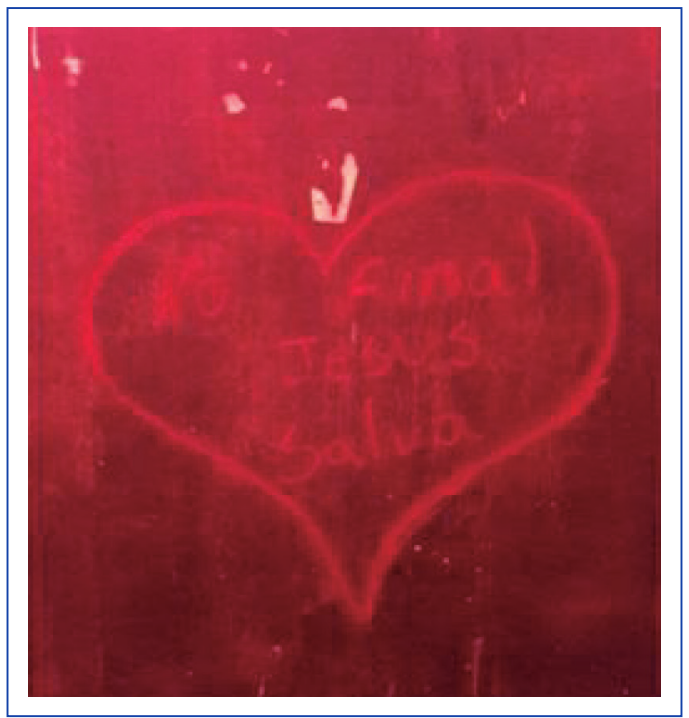

Fonte: Foto tirada pelos autores (2017).

Parece que o final expresso pelo escrito em batom e esperado pela pecadora delineia a possibilidade de uma identidade fragmentada no tempo atual ou, pelo menos, enquanto a evangélica prostituta continuar nesta profissão. No futuro, tudo dará certo: ela será redimida e poderá ser em sua totalidade, sem vergonha, sem desprezo próprio nem de terceiros. A mensagem, no entanto, tem de estar ostensivamente presente para intermediar o tempo entre o estigma e a "salvação".

Notamos que as prostitutas são comumente estigmatizadas "[...] não por estar a cometer qualquer infração legal, mas pela sua divergência face aos valores dominantes que regulam a sexualidade feminina e estabelecem uma ideia moral de ordem" (SACRAMENTO e RIBEIRO, 2015, p. 200). São representadas como putas e mulheres de vida fácil que em diversos momentos se veem como a escória da sociedade (RIBEIRO, SILVA, SCHOUTEN et al., 2007) e que fazem um trabalho sujo para esta mesma sociedade. São profissionais que se permitem expor à ocultação, ao desconhecimento, à rejeição e à negação; o que, frequentemente, redunda em lacunas de invisibilidade e esquecimento, constituindo o que convencionalmente a sociedade rotula como trabalhos marginais (CANHOLI JÚNIOR, LIMA, LIMA et al., 2016). Tendo seus processos de identificação e construção identitária estruturados em um cenário marginal e desmoralizado, o seu estigma pode ser compreendido como um tipo de identidade (GOFFMAN, 1959).

As análises realizadas permitiram identificar que as prostitutas evangélicas, foco deste estudo, encontram o constante e dinâmico desafio de construir e reconstruir cotidianamente suas identidades pessoais (CAMPOS e OGUISSO, 2008; AVELAR e PAIVA, 2010) por meio da religião, no sentido de encontrar aquilo que ela é e o que os outros esperam que ela seja (WHETTEN e GODFREY, 1998; BOULART e LANZA, 2007). Paradoxalmente, nesse processo de reconhecer-se, analisar-se e aprovar-se, religião e moralidade possibilitam comparações distintivas e hierarquizantes sobre o modo como nos comportamos em relação a nós mesmos e aos outros (TAYLOR, 1997), avaliando o que é certo e errado, aceitável moralmente ou não. Em termos agregados, além de a religião permear a transição entre humanização e precariedade do trabalho (DAVEL e VERGARA, 2001), às prostitutas evangélicas ela funciona como um dispositivo para que elas se reconectem do submundo da prostituição ao mundo "digno", ao transcendente, à sociedade (MOORE, 2004). Assim, ainda que evangélicas fervorosas, as profissionais do sexo ainda não são convertidas em ex-prostitutas. Somente essa identificação possibilitará, segundo estas profissionais, a salvação moral, a ressignificação e o reposicionamento de suas identidades. Logo, para se ter um fim diferente daquelas prostitutas das passagens bíblicas, é necessário se converter e estar "do outro lado" (LOPES, 2017), ainda que a prostituição seja sua principal atividade e seu sustento familiar. 


\section{CONSIDERAÇÕES FINAIS}

No Brasil, a prostituição reúne diversos estigmas impressos por determinadas compreensões do imaginário social. Quando então mencionamos o fato de a prostituição ser executada por mulheres evangélicas, os estigmas e paradoxalidades parecem se acentuar, dado que, aos olhos da sociedade brasileira dita "comum", trata-se de uma questão inaceitável, blasfematória e fortemente repudiada. Nesse sentido, há um intenso choque de princípios, valores e identidades socialmente tidos como antagônicos.

Como reflexo deste contexto, as análises neste estudo permitiram identificar, em primeira instância, um profundo sentimento de culpa e, em alguns casos, dor e sofrimento das prostitutas evangélicas, dado o paradoxo de comungar de valores e crenças pessoais intrinsecamente opostos às práticas de seu ofício. Contudo, questões mais objetivas como o sustento e a manutenção própria e da família levaram-nas a se sujeitarem a esta realidade. Nesse aspecto, a ambivalência caracteriza-se pela dificuldade que se pode perceber, por parte das entrevistadas, em ordenar e dar sentido ao seu próprio mundo, deixando transparecer contradições, autoestigmatizações, sentimentos complexos e controversos sobre as representações de si. Esses paradoxos expressos em situações ambivalentes apresentam indícios de que acentuam, no caso das prostitutas evangélicas, o processo de fragmentação e deterioração identitária.

Para lidar com tais estigmas, as entrevistadas se amparam em estratégias fortemente ambivalentes, buscando alicerçar-se em uma realidade possível em meio às "manchas" que sobre elas são impressas. Interessante considerar ainda que os discursos das entrevistadas evidenciam que elas se condenam e se redimem com base em ensinamentos bíblicos, ou seja, o mesmo "instrumento" é utilizado para automutilação simbólica e o auto perdão. Nesse sentido, paradoxalmente, a religião, ao mesmo tempo que intensifica as dores da imoralidade, atenua a carga do pecado imposto a elas em virtude de seu trabalho.

Desse modo, este estudo pretende contribuir e avançar teoricamente nos Estudos Organizacionais sobre a construção identitária de uma categoria de profissionais ainda pouco explorada pela área, tendo em vista o estigma e a marginalização que envolvem a prostituição. As descobertas empíricas e a originalidade do objeto de pesquisa do presente trabalho, isto é, as prostitutas evangélicas, evidenciaram especificidades em relação às suas identidades. Assim, o intuito foi problematizar e convidar o leitor a refletir sobre o papel que as prostitutas, em especial as prostitutas evangélicas, ocupam em nossa sociedade moralista e pautada em dogmas religiosos. Além disso, buscou-se contribuir para o empoderamento dessas profissionais ao ouvi-las e fazer com que suas vozes e anseios sejam lidos e debatidos em outras instâncias. Ainda que esse empoderamento não seja tão expressivo, acredita-se que o processo de reflexão acadêmica sobre a realidade dessas profissionais seja um passo importante para tirá-las da invisibilidade social e para que mudanças em relação a estigmatização e naturalização de estereótipos aconteçam.

Por fim, os achados deste estudo permitem alguns questionamentos: moral religiosa e liberdade sexual são intrinsecamente opostas? Dado que, assim como afirma Lhuilier (2010), todas as profissões possuem aspectos do "trabalho sujo", em algumas em maior proporção e representatividade que em outras, em que as contradições aqui discutidas se diferem de outros contextos profissionais, socialmente marginalizados ou não? Nesse sentido, sugere-se como agenda de futuros estudos: analisar a relação entre religiosidade e outras categorias dos trabalhos considerados moralmente sujos; analisar a relação entre a prostituição e religiões de outras doutrinas, como a católica e as de matrizes africanas; analisar o processo de construção de identidades de categorias de "trabalhadores sujos" que compõem as chamadas profissões "imperiais", ou seja, de grande representação e prestígio social, como médico legista, advogado criminalista, dentre outros que diariamente têm de "fazer o trabalho sujo" de uma profissão "limpa". 
Entre o sagrado e o profano: identidades, paradoxos e ambivalências de prostitutas evangélicas do baixo meretrício de Belo Horizonte
Jefferson Rodrigues Pereira | José Vitor Palhares dos Santos Alice Gerlane Cardoso da Silva | Kely Cesar Martins de Paiva Alexandre de Pádua Carrieri

\section{REFERÊNCIAS}

ALVESSON, M.; KÄRREMAN, D. Decolonializing discourse: critical reflections on organizational discourse analysis. Human Relations, v. 64, n. 9, p. 1121-1146, 2011.

ALVESSON, M.; WILLMOTT, H. Identity regulation as organizational control: producing the appropriate individual. Journal of Management Studies, v. 39, n. 5, p. 619-644, 2002.

ANGROSINO, M. Etnografia e observação participante. Porto Alegre: Artmed, 2009.

ASHFORTH, B. E.; KREINER, G. E. "How can you do it?": dirty work and the challenge of constructing a positive identity. Academy of management Review, v. 24, n. 3, p. 413-434, 1999.

AVELAR, V. L. L. M.; PAIVA, K. C. M. Configuração identitária de enfermeiros de um serviço de atendimento móvel de urgência. Revista Brasileira Enfermagem, v. 63, n. 6, p. 1010-1018, 2010.

BARRETO, L. C. Prostituição, gênero e trabalho. Rio de Janeiro: Multifoco, 2013.

BARROS, L. A. Mariposas que trabalham: uma etnografia da prostituição feminina na região central de Belo Horizonte. Jus Navigandi, v. 8, n. 1, 2005.

BASSERMANN, L. The oldest profession: a history of prostitution. New York: Dorset House Publishing, 1994.

BASTOS, S. O Estado Novo e os seus vadios: contribuição para o estudo das identidades marginais e da sua repressão. Lisboa: D. Quixote, 1997.

BERGER P. L.; LUCKMANN, T. A construção social da realidade. Petrópolis: Vozes, 2011.

BERGER, P. L. O dossel sagrado: elementos para uma teoria sociológica da religião. São Paulo: Paulinas, 1985.

BIRMAN, P. "Feitiçaria, Territórios e Resistências Marginais". Mana, v. 15, n. 2, p. 321-348, 2009.

BLITHE, S.J.; WOLFE, A. W. Work-life management in legal prostitution: Stigma and lockdown in Nevada's brothels. Human Relations, v. 70, n. 6, p. 725-750, 2017.

BORGES, L. O.; MOURÃO, L. O trabalho e as organizações: atuação a partir da psicologia. Porto Alegre: Artmed, 2013

BOULART, I. B.; LANZA, M. B. F. Identidade das Pessoas e das Organizações. Revista Administração e Diálogo, v. 9, n. 1, p. 1-18, 2007.

BOURDIEU, P. A Dominação Masculina. Rio de Janeiro: Bertrand Brasil, 1999.

BRASIL. Conselho Nacional de Saúde. Resolução 510, de 07 de abril de 2016. Diário Oficial da União (DOU), n. 98, 24 maio 2016. Disponível em: <http://www.conselho.saude.gov.br/resolucoes/2016/Reso510. pdf>. Acesso em: 01 mar. 2019.

BREWIS, J.; LINSTEAD, S. 'The worst thing is the screwing': Context and career in sex work. Gender, Work \& Organization, v. 7, n. 3, p. $168-180,2000$.

BROWN, A. D. Identities and identity work in organizations. International Journal of Management Reviews, v. 17, n. 1, p. 20-40, 2015.
CABANA, R. D. P. L.; ICHIKAWA, E. Y. As identidades fragmentadas no cotidiano da Feira do Produtor de Maringá, Organizações \& Sociedade, v. 24, n. 81, p. 285-304, 2017.

CAMPOS, B. M.; MARIANI, C. M. C. B. Peter Berger e Rubem Alves: religião como construção social entre a manutenção do mundo e a libertação. Protestantismo em Revista, v. 36, p. 3-20, 2015.

CAMPOS, P. F. S.; OGUISSO, T. A Escola de Enfermagem da Universidade de São Paulo e a reconfiguração da identidade profissional da Enfermagem Brasileira. Revista Brasileira de Enfermagem, v. 61, n. 6, p. 892-898, 2008.

CANHOLI JUNIOR, C. et al. Sentidos do trabalho para trabalhadores do saneamento básico. In ENCONTRO DA ANPAD, 40., 2016, Costa do Sauípe. Anais... Costa do Sauípe: Anpad, 2016.

CARNEIRO, L.C.; SERAFIM, M.C.; TEZZA, R. Uma Análise Bibliométrica da Relação entre Ética e Espiritualidade/Religiosidade nas Organizações. Revista Interdisciplinar de Gestão Social, v. 7, n. 2, p. 143-166, 2018.

CARRARA, S. Utopias sexuais modernas: uma experiência religiosa Americana. Etnográfica, v. 4, n. 2, p. 355-368, 2000.

CASTELLS, M. O poder da identidade. São Paulo: Paz e Terra, 1999.

CUNHA, L.A. Prostituição e religião: a trajetória religiosa de mulheres que praticam a prostituição na região de Santo Amaro - São Paulo. 2014. Dissertação (Mestrado em Ciências da Religião) - Universidade Católica de São Paulo, São Paulo, 2014.

DABHOIWALA, F. As Origens do Sexo: uma história da primeira revolução sexual. São Paulo: Globo, 2013.

DAVEL, E.; VERGARA, S.C. Gestão com pessoas e subjetividade. São Paulo: Atlas, 2001.

DEVOTTA, K. et al. Enriching qualitative research by engaging peer interviewers: A case study. Qualitative Research, v. 16, n. 6, p. 661680, 2016.

DIDI-HUBERMAN, G. Sobrevivência dos vagalumes. Belo Horizonte: Editora UFMG, 2011.

DOWN, S.; REVELEY, J. Between narration and interaction: situating first-line supervisor identity work. Human Relations, v. 62, n. 3, p. 379-401, 2009.

DUBAR, C. A socialização: construção das identidades sociais e profissionais. São Paulo: Martins Fontes, 2005.

DURKHEIM, E. Formas elementares da vida religiosa. São Paulo: Martins Fontes, 1996.

FAIRHURST, G. T.; COOREN, F. Organizational Discourse Analysis. In: CASSEL, C.; CUNLIFFE, A. L.; GRANDY, G. The Sage Handbook of Qualitative Business and Management Research Methods. London: Sage, 2018. p. 82-101.

FANGANIELLO, A.L.S. Profissionais do sexo e autoimagem na cidade de São Paulo. 2008. Disponível em: <https://sapientia.pucsp.br/ handle/handle/18753>. Acesso em: 01 mar. 2019.

FARIA, J. H. Análise de discurso em estudos organizacionais: as concepções de Pêcheux e Bakhtin. Teoria e Prática em Administração, v. 5, n. 2, p. 51-71, 2015. 
Entre o sagrado e o profano: identidades, paradoxos e ambivalências de prostitutas evangélicas do baixo meretrício de Belo Horizonte
Jefferson Rodrigues Pereira | José Vitor Palhares dos Santos Alice Gerlane Cardoso da Silva | Kely Cesar Martins de Paiva Alexandre de Pádua Carrieri
FERNANDES, M. E. R. Os paradoxos do processo identificatório na trajetória de diretores, gerentes e técnicos de duas empresas multinacionais de tecnologia. In ENCONTRO DA ANPAD, 33., 2009, São Paulo. Anais... São Paulo: Anpad, 2009.

GOFFMAN, E. The Presentation of Self in Everyday Life. New York: Anchor Books, 1959.

GOFFMAN, E. Estigma: notas sobre a manipulação da identidade deteriorada. Rio de Janeiro: Zahar, 1982.

GUNDOLF, K.; FILSER, M. Management research and religion: a citation analysis. Journal of Business Ethics, v. 112, n. 1, p.177-185, 2013.

HONNETH, A. Trabalho e reconhecimento: tentativa de uma redefinição. Civitas - Revista de Ciências Sociais, v. 8, n. 1, p. 46-67, 2008.

HOWARD, J. A. Social psychology of identities. Annual Review of Sociology, v. 26, p. 367-393, 2000.

HUGHES, E. C. Men and their work. Illinois: The Free Press of Glencoe, 1958.

LEITE, G. S. Pastoral da mulher marginalizada. Reflexões de uma mulher que viveu a prostituição. Tempo e Presença, São Paulo, n. 214, p. 23-25, nov. 1986.

LHUILIER, D. L'invisibilité du travail réel et l'opacité des liens santétravail. Sciences Sociales et Santé, v. 28, n. 2, p. 31-63, 2010.

LOPES, N. "Prostituição sagrada" e a Prostituta como objeto Preferencial de conversão dos "crentes". Religião e Sociedade, v. 37, n. 1, p.3446, 2017.

MACHADO, H. V. A identidade e o contexto organizacional: perspectiva de análise. Revista de Administração Contemporânea, v. 7, p. 51-73, 2003.

MANAIA, R. S. R. Os Poderes sobre a Prostituição: observações sobre o objeto. In CONGRESSO INTERNACIONAL DE HISTÓRIA, 5., 2011, Maringá. Anais... Maringá: Congresso Internacional de História, 2011. p. 2678-2687,

MARIANO, R. Neopentecostais. São Paulo: Loyola, 1999.

MARIZ, C. L. Ação social de Pentecostais e da Renovação Carismática Católica no Brasil. O discurso de seus líderes. Revista Brasileira de Ciências Sociais, v. 31, n. 92, p.1-16, 2016.

MIRANDA, C. Identidade: síntese das múltiplas identificações. São Paulo: Cabral Editora Universitária, 1998.

MITROFF, I. I.; DENTON, E. A. A Spiritual audit of corporate America: a hard look at spirituality, religion and values in the workplace. São Francisco: Jossey-Bass, 1999.

MONTEIRO, D. F. B. et al. Trabalho Sujo com a Morte: o Estigma e a Identidade no Ofício de Coveiro. Revista Interdisciplinar de Gestão Social, v. 6, n. 1, p. 77-98, 2017.

MOORE, L. Selling God American Religion in the Market space of Culture. New York: Oxford University Press, 2004.

ORLANDI, E. P. Análise de discurso: princípios e procedimentos. Campinas: Pontes, 2009.

PAIVA, G. J. Estudos psicológicos da experiência religiosa. Temas de Psicologia, v. 6, n. 2, p.153-160, 1998.

PÊCHEUX, M. El discurso: ¿estructura o acontecimiento? Décalages, v.1, n. 4, p.1-20, 2014.
PEREIRA, J. R. et al. 'O Show Tem Que Continuar': Encalços e Percalços do Ser/Estar Prostituta. Contextus - Revista Contemporânea de Economia e Gestão, v.16, n.3, p.151-180, 2018.

RIBEIRO, M. et al. Vidas na raia: prostituição feminina em regiões de fronteira. Porto: Afrontamento, 2007.

ROQUETE, F. F. et al. “¿Quién soy yo?” con la palabra, enfermeros supervisores de un hospital privado de Belo Horizonte. Enfermería Global, v. 11, n. 27, p. 259-274, 2012.

SACRAMENTO, O.; RIBEIRO, M. Mulheres marcadas: prostituição, ordem e exclusão. Cuadernos de trabajo social, v. 27, n. 1, p. 197209, 2014.

SANDERS, T. 'It's just acting': sex workers' strategies for capitalizing on sexuality. Gender, Work \& Organization, v. 12, n. 4, p. 319-342, 2005.

SILVA, K. A. T.; CAPPELLE, M. C. A. Sentidos do Trabalho Apreendidos por meio de Fatos Marcantes na Trajetória de Mulheres Prostitutas. Revista de Administração Mackenzie, v. 16, n. 6, p. 19-47, 2015.

SILVA, K. A. T.; CAPPELLE, M. C. A. O Trabalho na Prostituição de Luxo: Análise dos Sentidos Produzidos por Prostitutas em Belo Horizonte - MG. Revista de Gestão Social e Ambiental, v. 11, n. esp., p. 23-39, 2017a.

SILVA, K. A. T.; CAPPELLE, M. C. A. Um estranho no espelho? Identidade e constituição identitária na prostituição de luxo. In ENCONTRO DE GESTÃO DE PESSOAS E RELAÇÕES DE TRABALHO, 6., 2017, Curitiba. Anais... Curitiba: Pontifícia Universidade Católica do Paraná, 2017b. p. 1-9.

SILVA, R. R.; SIQUEIRA, D. Espiritualidade, religião e trabalho no contexto organizacional. Psicologia em Estudo, v. 14, n. 3, p. 557-564, 2009.

SOUTHGATE, E.; SHYING, K. Researchers as dirty workers: cautionary tales on insider-outsider dynamics. Qualitative Research in Organizations and Management: An International Journal, v. 9, n. 3, p. 223-240, 2014.

SOUZA, M. M. P.; CARRIERI, A. P. Identidades, práticas discursivas e os estudos organizacionais: uma proposta teórico-metodológica. Cadernos EBAPE.BR, Rio de Janeiro, v. 10, n. 1, p. 40-64, 2012.

SPURGEON, C.H. Eleição. São José dos Campos: Editora Fiel, 1996.

STARK, R.; BAINBRIDGE, W. S. Religion, deviance, and social control. Routledge, 2013.

TAYLOR, C. As fontes do self: a construção da identidade moderna. São Paulo: Loyola, 1997.

TRACEY, P. Religion and organization: A critical review of current trends and future directions. The Academy of Management Annals, v. 6, n. 1, p. 87-134, 2012.

WAGENAAR, H. Democracy and prostitution: deliberating the legalization of brothels in the Netherlands. Administration \& Society, v. 38, n. 2, p. 198-235, 2006.

WEBER, M. A ética protestante e o espírito do capitalismo. São Paulo: Pioneira, 1967.

WEST, J. Prostitution: Collectives and the politics of regulation. Gender, Work \& Organization, v. 7, n. 2, p. 106-118, 2000.

WHETTEN, D.; GODFREY, P. Identity in organizations. London: Sage Publications, 1998. 
Jefferson Rodrigues Pereira

ORCID: https://orcid.org/0000-0003-4837-4063

Doutorando em Administração na Universidade Federal de Minas Gerais (UFMG), Belo Horizonte - MG, Brasil. E-mail: jeffersonrodrigues@live.com

José Vitor Palhares dos Santos

ORCID: https://orcid.org/0000-0002-9190-3875

Doutorando em Administração na Universidade Federal de Minas Gerais (UFMG); Professor substituto no Instituto Federal de Educação, Ciência e Tecnologia de Minas Gerais (IFMG), Ribeirão das Neves - MG, Brasil. E-mail: titopalhares@hotmail.com

Alice Gerlane Cardoso da Silva

ORCID: https://orcid.org/0000-0002-8084-6019

Doutoranda em Administração na Universidade Federal de Minas Gerais (UFMG), Belo Horizonte - MG, Brasil. E-mail: alicegerlane@hotmail.com

Kely Cesar Martins de Paiva

ORCID: https://orcid.org/0000-0002-5185-9072

Doutora em Administração pela Universidade Federal de Minas Gerais (UFMG); Professora adjunta na Universidade Federal de Minas Gerais (UFMG), Belo Horizonte - MG, Brasil. E-mail: kelypaiva@face.ufmg.br

Alexandre de Pádua Carrieri

ORCID: https://orcid.org/0000-0001-8552-8717

Doutor em Administração pela Universidade Federal de Minas Gerais (UFMG); Professor Titular na Universidade Federal de Minas Gerais (UFMG), Belo Horizonte-MG, Brasil. E-mail: alexandre@face.ufmg.br 